\title{
FORTY YEARS OF NEPHROSIS IN CHILDHOOD*
}

\author{
BY \\ DAVID LAWSON, ALAN MONCRIEFF and WILFRID W. PAYNE \\ From The Hospital for Sick Children, Great Ormond Street, and the Institute of Child Health, London
}

(RECEIVED FOR PUBLICATION JUNE 19, 1959)

This article is an attempt to relate the present-day outlook on nephrosis in childhood with the 'natural history' of the disorder as it was seen at The Hospital for Sick Children, Great Ormond Street, in the days before modern treatment was available. The first period of the study is the responsibility of one of us (D.L.) and covers the years 1917-38. During the war years in-patient care of the children attending this hospital was widely dispersed and records are not always available. With the opening up of the hospital to more than a handful of patients in 1945 and the development of a new index system the study starts again and covers up to 1956-7. This period falls into two parts: for 1945-51 it had become possible to prevent and treat infection in children with nephrosis by means of sulphonamides and antibiotics; from 1951 steroids became available, at first in limited supply for selected cases, and in 1955 freely available for all cases as required.

The Hospital for Sick Children, Great Ormond Street has a large turn-over of patients and serves a wide area. This means that large numbers of case records have to be read and details checked before a child can be accepted as qualifying for inclusion in the series. It also means that follow-up of children, especially after they have passed the age for attendance at the hospital, presents many difficulties.

\section{Definitions}

For the purpose of this study the term nephrosis is applied to a syndrome presenting four essential characteristics, namely oedema, gross proteinuria, lowered plasma albumin and raised blood cholesterol.

The disorder presents, usually in the absence of any constitutional disturbance or other symptomatology, with the unheralded onset of generalized oedema. In severe cases the child becomes universally waterlogged in the course of a few days,

* A summary of this paper was given at the IX International Paediatric Congress, Montreal, in July, 1959. although a slower but steady increase in oedema over the course of two or three weeks is commoner. The urine, which has usually been unremarkable in quality, although often moderately diminished in quantity, is found to contain from 500 to $2,000 \mathrm{mg} . \%$ of protein but only a moderately increased red cell content. Addis counts of up to 10 million are not uncommon but the haematuria seldom amounts to more than this and is almost never macroscopic. The serum cholesterol is usually raised at the 'onset' but, if not, it steadily rises in the course of a few weeks to levels between 400 and $2,000 \mathrm{mg}$. \%. The plasma albumin concentration is always markedly decreased and may be below $1 \%$.

An infection often precedes the clinical onset but it is seldom clearly streptococcal and is more often in the nature of a common cold or bronchitis. Subsequently, it is often found that such infections will precipitate a return of, or an increase in the degree of, oedema and it is easy to understand that such an episode may first bring the hitherto subclinical disorder to light. The oedema may last for a few weeks only or may persist over months or years with alternating remission and relapse. When onset or relapse can be closely studied biochemically, it is found that the oedema is the last of the signs to appear in relapse and the first to disappear in remission, with the possible exception of proteinuria. After such a variable course all the manifestations may clear and the disorder may appear to be healed. Death may occur in periods of severe oedema from biochemical and waterbalance disturbances or from overwhelming bacterial infection to which these children are particularly subject; or there may be a gradual or rapid superimposition, at any phase, of the features of generalized renal failure and hypertension with final death in uraemia. The transient occurrence of nitrogen retention or hypertension, particularly common in periods of increasing oedema, does not however itself presage such a termination.

In the 1945-57 series clinical notes and biochemical 
records have been fairly complete; most of the cases could be followed up and re-examined and all were within the memory of authors or colleagues.

The extraction and definition of the 1917-38 series was more difficult because (1) records, and in particular biochemical investigations, were less complete; (2) there were no existing follow-up studies as out-patient records for the period did not survive the Second World War; and (3) the unity of this disease was not recognized at the time and cases were found under a wide range of diagnostic headings. Biochemical criteria were applied wherever possible, but in many cases a subjective element had to be introduced.

When the question of differentiation between nephrosis and acute glomerulo-nephritis arose, main reliance was placed on the following contrasting features in the natural history of acute glomerulonephritis: (1) sudden onset with urinary signs, often within 10-14 days of a streptococcal infection; (2) transient nature of the oedema; (3) rapid rise and fall in any transient initial nitrogen retention and hypertension; and (4) normal blood cholesterol and plasma protein at clinical onset.

\section{Classification}

For the purpose of analysis the cases have been placed in one of the four following groups:

Inactive. This means the absence of the four essential criteria already quoted. Albuminuria must not exceed $50 \mathrm{mg}$. per $100 \mathrm{ml}$. The electrophoretic pattern of the plasma proteins is normal.

Latent. There is no oedema but albuminuria is above $50 \mathrm{mg}$. per $100 \mathrm{ml}$. and blood urea and cholesterol levels may or may not be normal.

Active. This group consists of cases with the complete, potentially reversible nephrotic syndrome just described, who may have transient increases in their blood urea and blood pressure, and also cases who have progressed to the irreversible uraemic stage, as judged by a persistently high and increasing blood urea and an increasing blood pressure.

Dead. The cause may not always be directly related to the nephrosis.

The second group is the most controversial and must be further discussed. By oedema in a followup series is meant essentially the pre-tibial oedema of the child, otherwise apparently well, who is attending the out-patient department, not the waterlogged condition of the in-patient which fluctuates so much and not always for obvious reasons. There is no simple way of screening patients other than by looking for the pre-tibial oedema. All such cases will have some degree of albuminuria. When the oedema goes the child is clinically normal, but there may or may not be albuminuria of over $50 \mathrm{mg}$. per $100 \mathrm{ml}$. If there is no such albuminuria then the child will almost certainly come into the inactive group provided that the blood chemistry is normal. Strictly speaking therefore inactive means clinically normal (i.e. no oedema) and chemically normal. The latent group seems to contain three subdivisions: (a) clinically normal but still albuminuria of over $50 \mathrm{mg}$. per $100 \mathrm{ml}$; (b) clinically normal but both albuminuria and abnormal chemistry; and (c) clinically normal, no albuminuria but blood chemistry not quite normal. It is recognized that this latent stage may persist, but it only appears in a very small number of the patients whose records have been analysed in the 1945-57 series and the transfer of such patients to either the inactive or active groups will not affect the main conclusions.

\section{Description of Search (1917-38 Series)}

The in-patient case records for this period are bound in volumes at the end of which is a diagnostic index prepared by the registrar. All these indices were searched and every case history examined in which there appeared the remotest possibility that it might be a case of nephrosis. These diagnostic terms included every case in which the word nephritis of any kind was used and any in which the words oedema or toxic oedema were used. This resulted in a close study of the records of 1,500 cases. The greatest care was taken to make this selection as accurate as possible, but in certain cases recourse had to be made to something closer to intuition than to scientific study in view of the paucity of records. The author (D.L.) who carried out this part of the work is however satisfied that the diagnosis was almost certainly correct in every case included and any doubtful ones were discarded.

Analysis. The total number of cases found in this way was 78 . Of these 18 had died during the first or subsequent admission and 60 had been discharged and lost from the records (Table 1).

TABLE 1

SEARCH AND FOLLOW-UP (1917-38 SERIES)

\begin{tabular}{|c|c|c|c|c|}
\hline In-patients' Records Searched & . & . & $\ldots$ & 1,500 \\
\hline $\begin{array}{l}\text { Accepted as nephrosis } \ldots \\
\text { Died in hospital } \ldots \\
\text { Follow-up attempted } 1953 \\
\text { Follow-up failed } 1953 \\
\text { Followed up } 1953\end{array}$ & $\begin{array}{l}\cdots \\
\cdots \\
\cdots \\
\cdots\end{array}$ & $\begin{array}{l}\cdots \\
\cdots \\
\cdots \\
\cdots\end{array}$ & \begin{tabular}{l|}
$\cdots$ \\
$\cdots$ \\
$\cdots$ \\
$\cdots$
\end{tabular} & $\begin{array}{l}78 \\
18 \\
60 \\
44 \\
16\end{array}$ \\
\hline
\end{tabular}

An attempt was made in 1953 to trace these 60 cases. Letters were sent to them at the recorded addresses and if no reply was received a further letter was sent. In a number of cases the patients could be traced at these addresses and in others 
information was given by the present occupier which led to their successful tracing subsequently. This search was completely unsuccessful in $\mathbf{4 4}$ of the 60 cases. Sixteen were successfully traced and of these five had died (Table 2).

TABLE 2

ANALYSIS OF 16 CASES SUCCESSFULLY FOLLOWED UP IN 1953 (1917-38 SERIES)

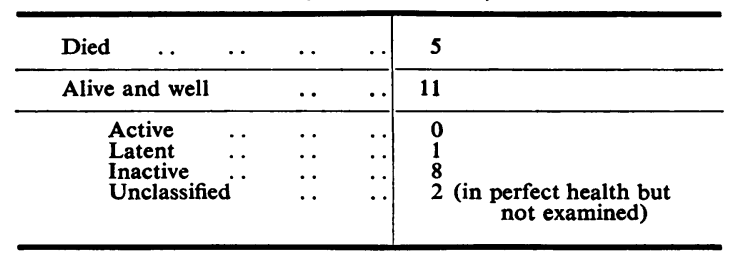

The remaining 11 were asked to come to the out-patient department for clinical and biochemical examination and nine did so. None of these had had any clinical relapse since his admission to hospital in childhood. All were in perfect health and none showed any clinical or biochemical evidence of activity or of sequelae of any kind, except for one woman who had borne children without mishap but whose urine contained $100 \mathrm{mg} . \%$ of protein. This technically places her in the latent rather than the inactive group. The remaining two were unable to come but sufficient information could be obtained to ensure that they were in perfect health.

Causes of Death (1917-38 Series). The 23 known deaths in this series have been classified as follows (see Table 3):

TABLE 3

ANALYSIS OF CAUSES OF DEATH (1917-38 SERIES)

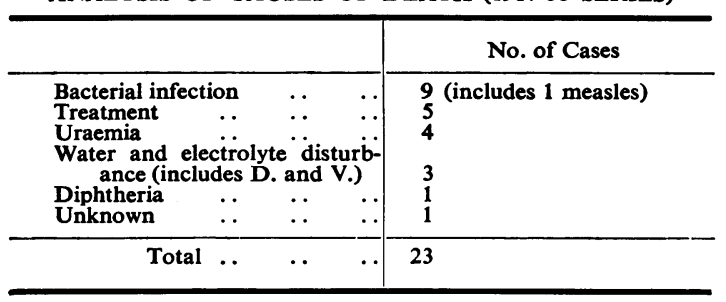

(1) INFECTION (nine cases). In all cases this was a bacterial infection with the exception of one child who died in a severe attack of measles. In the majority of cases the infection took the form of cellulitis, peritonitis and pneumonia, often accompanied by a septicaemia. There have been excluded from this heading infections which were the direct result of treatment.

(2) Disturbances of Water and Electrolyte BALANCE (three cases). This includes children who died from overwhelming oedema and also those in whom the cause of death was given as 'gastroenteritis'.

(3) Uraemia (four cases). Children who died in chronic uraemia with or without hypertension.

(4) Death due to Treatment (five cases). This includes two children who died suddenly following over-rapid paracentesis, one who died of postoperative pneumonia following a renal biopsy, one who died with convulsions without previous nitrogen retention in the post-operative period following a decapsulation operation, and one who died following decapsulation, paracentesis and subsequent wound infection.

(5) UNClASSIFIED (two cases). One appears to have been in perfect health for some years following discharge but died of diphtheria, and one died after discharge but the cause of death is unknown.

Of 21 cases in which the cause of death is known, therefore, all but four are deaths which could probably have been avoided had modern techniques of fluid and electrolyte balance and modern chemotherapeutic agents been available, and if methods now known to be useless and dangerous had not been used.

Estimate of Mortality (1917-38 Series). Of the total of 78 cases 18 , or $23 \%$, died during an initial or subsequent admission to The Hospital for Sick Children. In view of the incompleteness of the follow-up it is not possible to make a very accurate assessment of the subsequent mortality of the cases who were discharged alive. The first question to be answered is whether or not it is reasonable to assume that the 16 cases who could be traced were a representative sample of the 60 in which the attempt was made. This turns on the question of whether it is likely to be more difficult to trace patients who have died than to trace those who have survived.

TABLE 4

ROUGH ESTIMATE OF MORTALITY (1917-38 SERIES)

\begin{tabular}{|c|c|c|}
\hline $\begin{array}{l}\text { No. in series } \\
\text { Death in hospital } \\
\text { Deaths after discharge } \\
\text { to } 19 \text { out of } 60\end{array}$ & 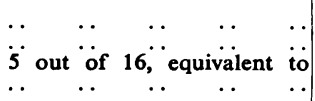 & $\left.\begin{array}{l}78 \\
18 \\
19\end{array}\right\}=37$ \\
\hline$y$ & 3 & \\
\hline
\end{tabular}

It is in fact the families rather than the individual patients who are being traced, and there seems no reason to think that it would be more difficult to trace the family of a child who had died than of one who had survived, although it is possible that the families of children who have died might be less willing to reply if they received the letter. Of the 44 untraceable cases, in all but four the follow-up letters were returned by the Post Office marked 'Not known at this address'. There were only four cases 
in which letters were not so returned by the Post Office and had therefore presumably been accepted at the address given. In these circumstances it is considered reasonable to assume that the 16 cases traced may be regarded as a representative sample of the 60 and the approximate overall mortality of the series is as follows: Five of the 16 are dead; therefore of the total of 60 it may be assumed that 19 are dead. To these 19 presumed dead must be added the 18 who are known to have died while in hospital, giving an overall mortality of $37 / 78$ or approximately $47 \%$ (Table 4 ).

It therefore appears that in the years 1917-38, before the days of antibiotics and steroids, the recovery rate was of the order of $50 \%$ and that of 21 cases in which the cause of death is known all but four (or approximately $20 \%$ ) were due to causes which might have been averted by modern methods of control of infection and water balance disturbance.

\section{Description of Search and Analysis (1945-57 Series)}

For this period of the study indexed diagnoses and a special list held by one of us (W.W.P.) were accepted in the first instance, and during the 12 years or so covered the number of children classified as nephrosis was 123 . Of these, five were private patients under the care of colleagues, and for various reasons records were not always complete nor was follow-up easy to arrange. They have therefore been omitted. Some of the remainder were seen as out-patients and transferred to other hospitals at once or after a short period. Their records have been used only in regard to age of onset and ultimate fate, if known. One of us (A.M.) read all the case records and reduced the data to a single pro forma sheet. This proved a fascinating but formidable task. Patients were often in hospital for long periods or were admitted on several occasions. (The record was held by one child admitted 23 times.) When no recent information existed this was obtained by seeing the child, by writing to the family doctor, to another hospital and so forth. As already mentioned, patients come to the hospital from a wide area and the tracing of them after discharge has been extremely difficult.* Altogether

\footnotetext{
* It may be mentioned in passing that successes in tracing included details obtained and contacts re-established in numerous ways. The police traced the address of one family; another patient was found after an announcement of her marriage engagement in The Times; the trail of one began in Wales, followed to a wrong part of East Africa, eventually finished in Central Africa and the child was seen in Out-patients when the father was next on leave. (She had actually made an apparently complete recovery which early records would not have suggested.) The Service authorities have been most helpful in tracing patients overseas, one going as far as Singapore. In other areas the health authorities have been most helpful and family doctors most willing to assist. One child in Malta, who was an in-patient, has been reported on whenever necessary.
}

failure has to be recorded for four children in the 1945-57 series. One is the child of a United States Air Force officer who has returned to the U.S.A. and, despite every possible effort on the part of the authorities, the present whereabouts are unknown. Three others were all going downhill shortly after the end of the war and cannot now be traced. Two of these were in fact rejected on further study of the records and are included in the 12 rejects to be mentioned later. Therefore of the true nephrotics in the series only two have been lost. After deducting lost patients, exclusions and transfers, there are 102 left for the purpose of estimating gross results and other factors (Table 5).

TABLE 5

PERIOD 1945-57

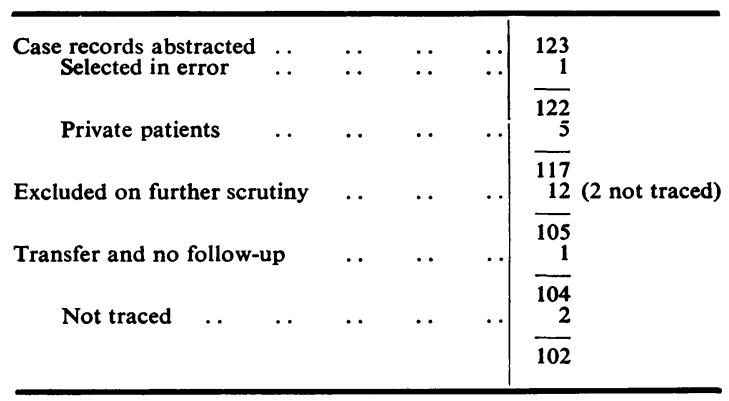

As already pointed out, this period can be divided into two main sections. Up to 1951 chemotherapy was available and then steroids were introduced, at first (since the supply was short) for limited and selected cases and by 1955 for all considered suitable. Detailed analysis as regards treatment will be given later. Here the gross results are considered according to the definitions already set out. In the 102 children successfully followed the disorder is considered to be inactive in 49 , latent in nine and active in six. The remaining 38 are dead. This gives a crude recovery rate of about $50 \%$ or the same as in the 1917-38 series when neither chemotherapy nor steroids were available. There is however a strong suggestion, supported by a small number of cases, that maintenance methods of using steroids have remarkably altered the picture.

A histogram (Fig. 1) illustrates the distribution on the basis of age at onset of the oedema, showing the usually accepted peak between 1 and 5 years of age. The deaths are very much the same proportionately for each age group throughout the series. The three children with a recorded onset before 6 months of age are the subject of a special note on congenital nephrosis on page 125 . 


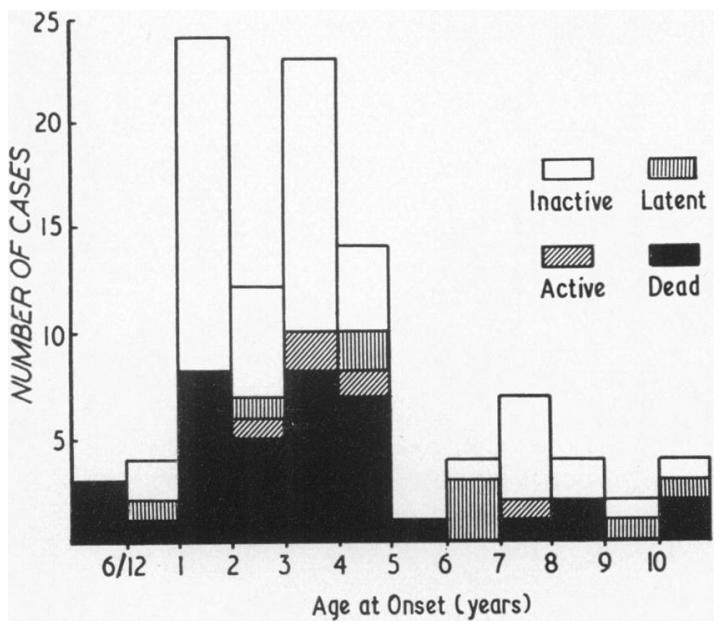

Fig. 1.-Histogram showing age at onset in 102 cases of nephrosis (1946-57 series).

The totals for the whole series are shown in Table 6. This shows a higher incidence in boys and a slightly higher mortality rate among boys than
TABLE 6

GROSS RESULTS (1945-57 SERIES)

\begin{tabular}{|c|c|c|c|c|c|c|c|}
\hline & & & & & Total & Boys & Girls \\
\hline \multicolumn{2}{|c|}{ Cases followed } & $\cdots$ & . & $\cdots$ & 102 & 59 & 43 \\
\hline $\begin{array}{l}\text { Inactive } \\
\text { Latent } \\
\text { Active } \\
\text { Dead }\end{array}$ & $\begin{array}{l}\ldots \\
\cdots \\
\cdots\end{array}$ & $\begin{array}{l}\cdots \\
\cdots \\
\cdots\end{array}$ & $\begin{array}{l}\cdots \\
\cdots \\
\cdots\end{array}$ & $\begin{array}{l}\ldots \\
\ldots \\
\ldots \\
\ldots\end{array}$ & $\begin{array}{r}49 \\
9 \\
6 \\
38\end{array}$ & $\begin{array}{r}25 \\
6 \\
5 \\
23\end{array}$ & $\begin{array}{r}24 \\
3 \\
1 \\
15\end{array}$ \\
\hline
\end{tabular}

girls. The numbers for latent or active cases are, as already mentioned, small in relation to the clear-cut groups of a satisfactory or fatal ending.

Table 7 gives details of the records of 12 patients in the 1945-57 series which, on final scrutiny, have not been included in the total of examples of nephrosis. Reasons for the rejection are given in the final column. The other columns indicate why at first sight the records appeared to justify inclusion. Since over half are known to be dead, and most of the others to be going down-hill, it seemed important to remove them from the series, otherwise they would have erroneously weighted the dead, active or latent groups.

TABLE 7

NEPHROSIS RECORDS REJECTED ON FINAL SCRUTINY (1945-57)

\begin{tabular}{|c|c|c|c|c|c|c|}
\hline \multirow[b]{2}{*}{ Name } & \multicolumn{5}{|c|}{ When First Seen } & \multirow[b]{2}{*}{ Reasons for Rejection } \\
\hline & $\begin{array}{l}\text { Age } \\
\text { (yr.) }\end{array}$ & Oedema & $\begin{array}{l}\text { Urinary Proteins } \\
(\mathrm{mg} \%)\end{array}$ & $\begin{array}{l}\text { Total Serum } \\
\text { Proteins } \\
\text { (mg.\%) }\end{array}$ & $\begin{array}{l}\text { Blood } \\
\text { Cholesterol } \\
(\mathrm{mg} . \%)\end{array}$ & \\
\hline Kenneth B. . & 12 & Nil & 440 & $4 \cdot 7$ & Not done & $\begin{array}{l}\text { No oedema; persistent haema- } \\
\text { turia; probably chr. nephritis }\end{array}$ \\
\hline Margaret D. . & $2 \frac{1}{2}$ & $+t+$ & 1,500 & $3 \cdot 6$ & 870 & $\begin{array}{l}\text { Raised blood urea; haematuria } \\
\text { type } 2 \text { nephritis from onset; acute } \\
\text { nephritis } 8 \mathrm{mth} \text {. before }\end{array}$ \\
\hline Raymond E. . & $7 \frac{1}{2}$ & $+t+$ & 700 & $3 \cdot 3$ & 470 & $\begin{array}{l}\text { Haematuria }++ \text {; scarlet fever } 3 \text { yr. } \\
\text { before; chronic nephritis }\end{array}$ \\
\hline Daniel H. & 8 & Minimal & 700 & $5 \cdot 62$ & 208 & $\begin{array}{l}\text { Hypertension; hepato-splenomeg- } \\
\text { aly; chronic nephritis }\end{array}$ \\
\hline Peter H. & 10 & ++ & Nil & $3 \cdot 02$ & 367 & $\begin{array}{l}\text { Never any albuminuria at G.O.S.; } \\
\text { ?'cured' before admission; oedema } \\
\text { for } 7 \text { weeks at age } 4 \frac{9}{4} \text { yr.; lost to } \\
\text { follow-up }\end{array}$ \\
\hline Michael H. . & $3 \frac{1}{2}$ & + & 140 & $4 \cdot 49$ & 386 & $\begin{array}{l}\text { Latent stage when first seen; died } \\
\text { chronic nephritis age } 10 \mathrm{yr} \text {. }\end{array}$ \\
\hline Michael K. . & $1 \frac{2}{3}$ & $++t$ & Gross & $3 \cdot 62$ & 394 & Transferred \\
\hline Peter L. & 1 & Nil & 800 & $4 \cdot 6$ & 356 & $\begin{array}{l}\text { No oedema at any time; persistent } \\
\text { red cells in urine }\end{array}$ \\
\hline Vera $\mathbf{M}$. & 9 & Slight & 800 & $4 \cdot 4$ & - & $\begin{array}{l}\text { Lost in follow-up; raised blood } \\
\text { pressure; acute nephritis aged } 9 \text { yr. }\end{array}$ \\
\hline Lothan M. . & 9 & Nil & 1,000 & $5 \cdot 6$ & - & $\begin{array}{l}\text { No oedema; blood urea } 148 \mathrm{mg} . \% \text {; } \\
\text { died chronic nephritis }\end{array}$ \\
\hline Christopher S. & 4 & Nil & 375 & $5 \cdot 9$ & 166 & $\begin{array}{l}\text { No oedema at first attendance; } \\
\text { latent in } 1951\end{array}$ \\
\hline Julian S. & $6 \frac{1}{2}$ & Slight & 400 & $5 \cdot 3$ & 206 & $\begin{array}{l}\text { Fibrocystic disease; cirrhosis of } \\
\text { liver; died aged } 7 \frac{1}{2} \text { yr. }\end{array}$ \\
\hline
\end{tabular}


Results of Treatment (1945-57 Series)

In the 1945-57 period a low salt and high protein diet was almost universally the basic treatment for cases of nephrosis while in hospital. Sometimes a diet which was almost salt-free was given, but sometimes it was found to produce abnormally low levels of serum sodium while oedema still persisted, and it is now rarely used. As well as this basic diet, various other forms of treatment were tried.

Thyroid. It was for a long time considered that thyroid had a place in the treatment of nephrosis and many cases were given this substance. Some cases were given thyroid up to the level of tolerance, shown usually by the onset of diarrhoea. In others normal therapeutic doses only were given $\left(\frac{1}{2}-1 \mathrm{gr}\right.$. thyroid daily).

Resins. With the introduction of resins, in a form suitable for therapeutic use, a group of children was treated using various types of resin. The results have been published in more detail elsewhere (Payne and Wilkinson, 1951).

Diuretics. Several types of diuretic have been used.

UREA. When urea is used as a diuretic it has been found necessary to give relatively large doses, such as $15 \mathrm{~g}$. a day, and at the same time to restrict the fluid intake. Until the blood urea reaches approximately $100 \mathrm{mg} . \%$, diuresis does not occur. When this level is reached diuresis follows in some cases. In others, unfortunately, no diuresis occurs. Increasing the blood urea to a higher level almost invariably produces such severe discomfort that it is impractical as a form of treatment. The misery of the child in these circumstances is most striking. When successful, the treatment can be maintained for many months.

WATER. Diuresis will result from forced water intake. Again this is by no means always possible. In some cases there is an initial retention of water and then any excess water given is excreted quantitatively. In other cases the excess water carries with it some of the oedema and a genuine diuresis occurs with loss of oedema.

Mercurial Diuretics. Mersalyl was the most frequently used and, as with other diuretics, there was sometimes an initial diuresis which in general was not maintained with further doses.

Non-Mercurial DiUReTics. Usually these have had no effect but occasional diuresis has occurred with the first few doses. Subsequent doses have proved ineffective.

Fever. In a few cases production of fever, either by measles or malaria, has been used, but the numbers are too small for use in this study. Usually there has been an initial loss of oedema followed in almost all cases by a return of oedema at varying intervals of time.

In Table 8 the results of individual treatments are shown, the results being classified as inactive, latent or active, according to the child's condition at the end of any particular period of treatment. The majority were on a basic low-salt high-protein diet and antibiotic treatment when necessary. Examination of this Table will, of course, show many more case treatments than the actual number of children. It will be seen that the number of cases classified as inactive occur mainly in the group which had rather prolonged treatment on the basic diet alone.

In two of the 36 treatments with urea the inactive state was reached, but the other diuretics, resin or water, produced only a transient improvement: five of 14 cases treated with water and 10 of 36 cases treated with urea became latent. Of the 23 cases receiving the basic treatment plus thyroid, five became inactive and six latent, and of the 49 case treatments in which no specific treatment other than the basic diet was given, 16 became inactive and 13 latent.

TABLE 8

RESULTS OF TREATMENT (1945-57 SERIES)

\begin{tabular}{|c|c|c|c|c|c|c|}
\hline \multirow{2}{*}{\multicolumn{3}{|c|}{ Treatment }} & \multirow{2}{*}{ Number } & \multicolumn{3}{|c|}{ Result } \\
\hline & & & & Active & Latent & Inactive \\
\hline 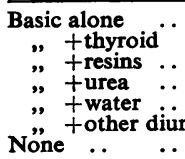 & 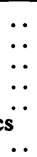 & $\begin{array}{l}\ldots \\
\ldots \\
\cdots \\
\cdots \\
\cdots \\
\ldots\end{array}$ & $\begin{array}{l}49 \\
23 \\
13 \\
36 \\
14 \\
19 \\
\end{array}$ & $\begin{array}{r}20 \\
12 \\
12 \\
24 \\
9 \\
18 \\
\end{array}$ & $\begin{array}{r}13 \\
6 \\
1 \\
10 \\
5 \\
1 \\
-\end{array}$ & $\begin{array}{r}16 \\
5 \\
0 \\
2 \\
0 \\
0 \\
10\end{array}$ \\
\hline
\end{tabular}

It will thus be seen that no better results were obtained when any specific treatment was given than when basic treatment alone was given. In fact, since the duration of the basic treatment was normally much longer than that of the specific treatment, the results appear much better.

The total number of cases not receiving steroids and becoming inactive in this group was 33: 10 recovered after being discharged and were presumably on no particular treatment at all.

Steroids. These became available in small amounts in 1951. A few cases were treated in the first years, and subsequently the use of steroids as the main treatment became general. Since 1951 the way in which steroids have been used has changed considerably and, largely owing to the more critical examination of results, the general aim of individual treatment has altered. Before steroid treatment 
there was no known method whereby the albuminuria could be controlled, and most clinicians planned the treatment of their cases on the basis of getting rid of the oedema and hoped that the albuminuria and other abnormalities would clear up in time, but the disappearance of the oedema was regarded as the therapeutic aim. (This point is discussed at greater length later.) It was on the disappearance and re-appearance of oedema that the reputation for frequency of spontaneous remissions and relapses in nephrosis was based. If the stricter criteria for apparent recovery are used, it will be seen that, although there is still a liability to relapse, it is by no means as frequent as was previously considered.

The records have been examined using these stricter criteria and, of the 15 children who reached the inactive phase and had had steroid treatment, two cases only relapsed, one recovered spontaneously and the other recovered after further treatment. In 22 cases of children not receiving steroids, who reached the inactive stage, only one case relapsed, and that case also made a spontaneous recovery. However, in the steroid-treated cases who have reached the inactive stage relatively recently, intercurrent infections may cause a transient return of the albuminuria, lasting from a few days to two or three weeks and disappearing without treatment.

Initially, short courses of steroids were given, either ACTH or cortisone. ACTH was usually given for eight to 10 days in varying doses, usually 20 to $40 \mathrm{mg}$. daily, and cortisone in doses from 100 to $200 \mathrm{mg}$. daily for approximately 10 days. In both cases at the end of that period treatment was abruptly stopped. This was called the short treatment. In most cases diuresis occurred and generally oedema disappeared but albuminuria, although frequently lessened, was generally still present and in most cases the oedema returned later on.

The next phase was to give larger doses, 200 to $300 \mathrm{mg}$. of cortisone, or the equivalent of prednisolone, or if ACTH was used, $80 \mathrm{mg}$. daily using the gel in divided doses. This treatment was maintained for approximately one month and then the steroids were tailed off fairly quickly, usually within two to three weeks. This type of treatment has been called long-term. In general in these cases the albuminuria disappeared only to reappear as the dose was being tailed off or very shortly afterwards.

In the next form of treatment, called maintenance treatment, steroid therapy has been maintained at a slowly decreasing level for much longer periods. There is much difference of opinion as to the ideal way of doing this. In the majority of the maintenance cases an initial month's treatment is given similar to that in the long-term, by which time there is usually no albuminuria and the plasma proteins are approaching normal while the cholesterol is falling. The dose is then cautiously reduced by 10 to $15 \%$ every week at first and later every fortnight. This slow reduction is continued as long as there is no albuminuria. Usually within two to three months the plasma proteins are chemically and electrophoretically normal and the cholesterol also has returned to a normal level. If these values are slow in returning to normal the therapy is continued for a longer period and the intervals between reductions are increased. If albuminuria returns during the period of reduction, the dose of steroid is increased until it disappears again. Reduction is then carried out more slowly.

In a few cases the intermittent high dosage treatment was used, $400 \mathrm{mg}$. cortisone three days in succession, followed by four days without steroid.

In assessing the final outcome, the cases have been divided into two groups, those who have received steroids and those who have not. The results are given in Table 9. The results in this Table are

TABKE 9

RESULTS OF TREATMENT WITH STEROIDS

\begin{tabular}{|c|c|c|c|c|c|c|}
\hline & & & \multicolumn{2}{|c|}{ No Steroids } & \multicolumn{2}{|c|}{ Steroids } \\
\hline & & & (no) & $(\%)$ & (no) & $(\%)$ \\
\hline Total cases & $\ldots$ & $\ldots$ & 62 & & 40 & \\
\hline $\begin{array}{l}\text { Inactive } \\
\text { Latent } \\
\text { Active } \\
\text { Dead }\end{array}$ & $\begin{array}{l}\ldots \\
\cdots \\
\cdots\end{array}$ & $\begin{array}{l}. \\
\cdots \\
\cdots\end{array}$ & $\begin{array}{r}33 \\
5 \\
4 \\
20\end{array}$ & $\begin{array}{r}53 \\
8 \\
7 \\
32\end{array}$ & $\begin{array}{r}16 \\
4 \\
2 \\
18\end{array}$ & $\begin{array}{r}40 \\
10 \\
5 \\
45\end{array}$ \\
\hline
\end{tabular}

somewhat unexpected. It appears that the results from steroid treatment are definitely inferior to those when no steroids are given. One possible explanation for this is the inclusion in the steroid group of cases carried over from the previous group which were already doomed to failure.

Table 10 is an analysis of the deaths in the two groups. Uraemia accounted for more than half the deaths but, whereas 10 cases of uraemic death

TABLE 10

CAUSES OF DEATH

\begin{tabular}{|c|c|c|c|c|c|}
\hline \multirow{3}{*}{\multicolumn{2}{|c|}{$\begin{array}{ll}\text { Uraemia } . . & \ldots \\
\text { Heart failure } & \ldots \\
\text { Infections ... } & \ldots \\
\text { Cystinosis } \\
\text { Pulmonary embolism } \\
\text { Electrolyte imbalance }\end{array}$}} & \multirow[b]{3}{*}{\begin{tabular}{l|}
$\because$ \\
$\cdots$ \\
$\cdots$ \\
$\cdots$ \\
$\cdots$ \\
$\cdots$
\end{tabular}} & \multirow{3}{*}{$\begin{array}{c}1917-1938 \\
\frac{4}{10} \\
\frac{7}{3} \\
5 \\
1\end{array}$} & \multicolumn{2}{|c|}{$1945-1957$} \\
\hline & & & & No Steroids & Steroids \\
\hline & & & & $\begin{array}{r}10 \\
1 \\
3 \\
2 \\
\frac{2}{2} \\
2\end{array}$ & $\begin{array}{r}10 \\
2 \\
\frac{2}{2} \\
\frac{2}{2}\end{array}$ \\
\hline Total & $\ldots$ & .. & 23 & 20 & 18 \\
\hline
\end{tabular}




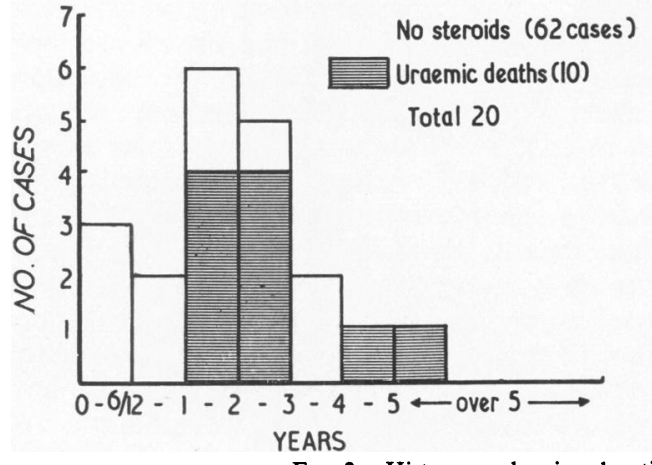

FIG. 2.-Histogram showing duration to death in 38 cases (1945-57 series).

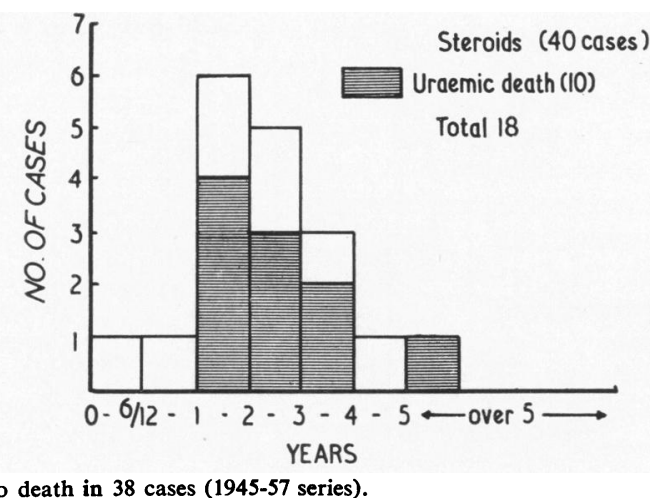

In Table 12A the length of time elapsed between onset of disease and cure, in the steroid and nonsteroid cases, is compared, and it will be seen that steroid treatment definitely produces more rapid cure.

In Table 12B the time relationship between onset and death shows that in the fatal cases there is no material difference.

Tables 12C and D show the ultimate result and the interval of time between onset of disease and the start of steroid therapy. There is no suggestion in these Tables that better results are obtained when steroid therapy is started early.

TABLE 12

\begin{tabular}{|c|c|c|c|c|c|c|}
\hline \multirow[t]{2}{*}{$\mathbf{A}$} & \multicolumn{5}{|c|}{ Time between Onset and Cure } & \multirow[b]{2}{*}{ Total } \\
\hline & $\begin{array}{l}<6 \\
\text { mth. }\end{array}$ & $\begin{array}{l}6-12 \\
\text { mth. }\end{array}$ & $\begin{array}{l}1-2 \\
\text { yr. }\end{array}$ & $\begin{array}{l}2-5 \\
\text { yr. }\end{array}$ & $\begin{array}{l}>5 \\
\text { yr. }\end{array}$ & \\
\hline $\begin{array}{l}\text { No steroid } \\
\text { Steroid }\end{array}$ & $\begin{array}{c}\text { (no.) } \\
5 \\
2\end{array}$ & $\begin{array}{c}\text { (no.) } \\
4 \\
2\end{array}$ & $\begin{array}{c}\text { (no.) } \\
4 \\
3\end{array}$ & $\begin{array}{c}\text { (no.) } \\
13 \\
9\end{array}$ & $\begin{array}{c}\text { (no.) } \\
- \\
\end{array}$ & $\begin{array}{l}33 \\
16\end{array}$ \\
\hline \multirow[t]{2}{*}{ B } & \multicolumn{5}{|c|}{ Time between Onset and Death } & \\
\hline & $\begin{array}{l}<6 \\
\text { mth. }\end{array}$ & $\begin{array}{l}\text { 6-12 } \\
\text { mth. }\end{array}$ & $\begin{array}{l}1-2 \\
\text { yr. }\end{array}$ & $\begin{array}{l}2-5 \\
\text { yr. }\end{array}$ & $\begin{array}{l}>5 \\
\text { yr. }\end{array}$ & Total \\
\hline $\begin{array}{l}\text { No steroid } \\
\text { Steroid }\end{array}$ & $\begin{array}{l}3 \\
1\end{array}$ & 2 & $\begin{array}{l}6 \\
6\end{array}$ & $\begin{array}{l}8 \\
9\end{array}$ & $\begin{array}{l}1 \\
1\end{array}$ & $\begin{array}{l}20 \\
18\end{array}$ \\
\hline \multirow[t]{3}{*}{ C } & \multicolumn{5}{|c|}{ Time from Start of Steroid Therapy to Cure } & \\
\hline & $\begin{array}{l}<6 \\
\text { mth. }\end{array}$ & $\begin{array}{l}6-12 \\
\text { mth. }\end{array}$ & $\begin{array}{l}1-2 \\
\text { yr. }\end{array}$ & $\begin{array}{l}2-5 \\
\text { yr. }\end{array}$ & $\begin{array}{l}>5 \\
\text { yr. }\end{array}$ & Total \\
\hline & 7 & 1 & 2 & 6 & & 16 \\
\hline \multirow[t]{2}{*}{ D } & \multicolumn{5}{|c|}{$\begin{array}{l}\text { Interval between Onset of Disease and } \\
\text { Steroid Therapy }\end{array}$} & \multirow{2}{*}{ Total } \\
\hline & $\begin{array}{l}<6 \\
\text { mth. }\end{array}$ & $\begin{array}{l}\text { 6-12 } \\
\text { mth. }\end{array}$ & $\begin{array}{l}1-2 \\
\text { yr. }\end{array}$ & $\begin{array}{l}2-5 \\
\text { yr. }\end{array}$ & $\begin{array}{l}>5 \\
\text { yr. }\end{array}$ & \\
\hline $\begin{array}{l}\text { Cure } \\
\text { Death } \ldots \\
\text { Latent or } \\
\text { active }\end{array}$ & $\begin{array}{l}8 \\
9 \\
2\end{array}$ & $\begin{array}{l}2 \\
3 \\
1\end{array}$ & $\begin{array}{l}3 \\
4 \\
1\end{array}$ & $\begin{array}{l}3 \\
2 \\
2\end{array}$ & & $\begin{array}{r}16 \\
18 \\
6\end{array}$ \\
\hline
\end{tabular}


In analysing the causes of death the hazards of treatment have to be considered. In the period 1917-38 it will be observed that a fair number of deaths can be attributed directly to treatment. It is not quite so obvious in the period 1945-57 but a suspicion by one of us (A.M.) that mersalyl was a dangerous treatment has been confirmed. The results in 12 cases treated with mersalyl are: inactive (1), latent (1), dead (10). These results strongly suggest that mersalyl in itself is dangerous. That it was used merely as a last resort was not found to be the case on examining the notes, since in most cases it was given in the first 12 months from the onset of disease.

It must be realized that steroid treatment is potentially dangerous and the group of cases we have treated shows the following results:

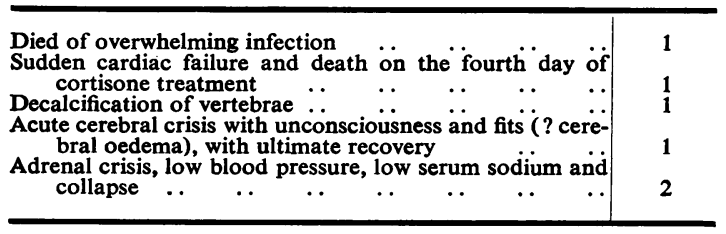

Thus, of the 18 steroid deaths, two can be attributed to steroid therapy, and both the cases of adrenal crisis could quite well have been fatal if they had not fortunately occurred while in hospital.

\section{Discussion}

The literature on nephrosis threatens to become unmanageable. This paper is essentially concerned with a presentation of facts as ascertained from a study of the disorder in childhood in hospital records for over 40 years. It is not proposed to discuss the pathology or pathogenesis. The definitions already set out indicate what sort of disease process is being considered. The results of treatment, with special reference to those obtained by the use of steroids, can usefully be compared with those presented by McCrory and Fleisher (1958), Metcoff (1958) and Riley and Scaglioni (1959). A useful historical survey was given by Mann (1958) on the occasion of the Bright centenary celebrations.

If the assumptions made in the section which considers the 1917-38 series are accepted as correct, then about half the patients are dead. In the 194557 series as a whole about half are either dead or in an active or latent phase. Some of those classified in the last two categories at the time of assessment may by now have moved or will move into the inactive group, so that broadly speaking these results probably show a slight improvement over the results of 1917-38, but certainly not as great an improvement as might have been expected with the better control of infection and, in the later cases, an active agent to attack what is probably the fundamental lesion which leads to the proteinuria. Again, if the 1945-57 group is broken down into those who did not receive steroids and those who did, there is no dramatic improvement with the new drugs, at any rate in the early years before the best method of using steroids was worked out. Indeed, taking the overall figures as shown in Table 9 , there is a $45 \%$ mortality rate in the steroid-treated cases compared with only $32 \%$ in those not receiving steroids, with $15 \%$ in each group still classified as latent or active.

A review of the causes of death in each of the three periods shows that $17 \%$ died of uraemia in the pre-antibiotic era, the remainder dying from causes such as infections, which now would be regarded as curable. Since the introduction of antibiotics the cause of death has changed and is now uraemia in over $50 \%$ of cases (Table 10 ).

However, deaths which would have been theoretically preventable still occur and in the final analysis uraemia and heart failure seem to be the expected causes of death in nephrotic children. A small unknown proportion of these uraemic deaths will be due to unavoidable errors in initial diagnosis, such as in those cases shown in Table 7 , which were retrospectively rediagnosed. Until more certain means of diagnosis are utilized (such as renal biopsy), this error will prevent an accurate prognosis, and therefore a proper evaluation of treatment, being made. From studies already published (Vernier, Farquhar, Brunson and Good, 1958) it is likely that in the majority of cases the correct diagnosis can be made in the early stages of the disease. Thus, a death rate from uraemia and heart failure of $23 \%$ of all recent cases (and it will become higher, since many of the still active cases are already uraemic) indicates that a proportion of 'pure nephrotic' children will die of uraemia. A small proportion will still die of intercurrent accidents, preventable or not; the remainder, if they can be kept alive, should recover. It is impossible to assess this figure accurately, but it is over $50 \%$ and probably about $60-70 \%$, as judged by the nonuraemic causes of death. Any treatment must have a 'cure' rate of about $80-90 \%$ before it can be regarded as of real value. Table 12 shows that the majority of deaths occur within the first five years of the disease, so it should be possible to determine if a given treatment has successfully prevented the development of uraemia when enough cases have been treated for over five years. At the present moment the evidence is only sufficient to indicate a promising trend. 
In considering the value of many of the remedies used, the aim of the treatment at the time must be borne in mind. Until quite recently the physician's primary aim was the cure of the oedema, with the hope that in due course the remaining pathological changes would cure themselves. With such an imperfect criterion of cure it is not surprising that relapses were many and frequent. Thus, when examining Table 8, all the latent results would have been called cures. Even with this proviso, it will be seen that the more common methods of therapy were quite ineffective when compared with the basic treatment (low-salt, raised-protein diet). In a small series of eight cases treated with measles and two with malaria, seven reached the latent stage, but only one became inactive without further relapses.

Since the oedema most frequently causes the patient to consult a doctor, its disappearance must have a good effect on the outlook of the child and his parents, although there is no direct evidence that removing oedema improves the prognosis. Thus it is reasonable to take non-specific measures which will help in its removal, providing that they are harmless. For example, urea, resins, water and occasionally non-mercurial diuretics are useful. For the same reason a low-salt diet is given.

Oedema, if severe, can be very distressing and can even endanger life. In these cases acupuncture of the dependant legs and abdominal paracentesis, both under antibiotic cover, have been used and occasionally a complete remission has followed.

Steroid treatment has undoubledly made a big change in the method of treating nephrosis. In the early days, when removal of oedema was the therapeutic aim, short eight to 10 day treatments were used with an initial gratifying effect but, as with previous methods, relapses occurred, which were more resistant to further treatment with steroids. The aim of treatment was altered to complete reversal of all pathological changes. Much longer terms of treatment were used and the results began to be more encouraging. While, as yet, no uniform method has been arrived at, the general principle is to give adequate dosage of a steroid preparation, the equivalent of 240 to $300 \mathrm{mg}$. cortisone daily. It does not appear to make much difference which of the new, less sodium-retaining steroids is used. Treatment is continued for six to 12 months according to the plan for reduction already mentioned. Clinically it seems that it needs many months to reverse completely the pathological changes in the glomerular basement membrane, if indeed this can be done. Since it is probable that some $20-30 \%$ of untreated patients will progress to irreversible renal damage, the essential fact to determine is whether in these cases it is possible to prevent this.

As has been pointed out, this can only be done when sufficient time has elapsed for such changes to develop-at least five years. This delay in making a judgment of cure is necessary since steroid therapy can remove the nephrotic symptoms for a time in cases in which the diagnosis is known not to be simple nephrosis. Until an adequate period has elapsed it is possible only to say that the latest results are promising in that a high percentage are reaching the inactive stage.

It has frequently been stated that liability to a return of nephrosis can never be eliminated. It is clear that clinical relapse is common if only the latent stage is reached. When the inactive stage is reached relapse is less frequent but may still occur. Many patients, whose nephrosis has been successfully treated with steroids, for some years tend to get transient albuminuria during fairly mild intercurrent infections. In a few this proceeds to a full relapse which may need a further course of steroids.

This raises the fundamental question of the aetiology of nephrosis. Should the condition be regarded as an inborn liability of the kidney to a special type of pathological response to certain insults, or should the pathological response be regarded as due to a specific insult, such as is believed to occur in acute nephritis following infection with certain types of streptococci? If the former view is held, it is unlikely that any form of treatment will prevent recurrence of symptoms even many years later. In the second possibility, once a cure is complete, relapse would only occur with a further specific insult. Such clinical evidence as exists suggests the former view as being possibly the more likely since occasionally relapses have recurred after many years of freedom from symptoms.

To sum up, the natural course of nephrosis, if intercurrent infections are adequately dealt with, is for at least $50 \%$ and probably nearer $60-70 \%$ of the patients to be cured, but there is also an inborn liability to relapse. There is in every series, based on clinical diagnosis alone, a small group with a different pathological basis and a bad prognosis. No treatment has yet been shown to improve the ultimate prognosis, although some treatments have worsened it. The most recent method of steroid therapy, while very promising, has undoubted hazards which must be balanced against the present uncertainty that permanent improvement in prognosis will occur.

Since delaying the start of steroid therapy does not seem to affect the ultimate result (Table 12D) and since a proportion of untreated cases remit 
spontaneously within a few months (Table 12A), delay of up to three months in starting steroid therapy is suggested to allow time to see if there are signs of spontaneous improvement. There is no evidence that any adjuvant treatment has a material effect, apart from the need to give an adequate protein diet and to keep the salt content low when there is oedema, especially during steroid therapy. Complete bed rest, except when there is gross oedema, is not necessary. A change from prolonged bed rest to reasonable activity at The Hospital for Sick Children caused no worsening of the prognosis and a decided improvement in the children's morale. Another advantage of permitting reasonable activity is that the child can be sent home and attend school when desired while still on steroid or other therapy.

It is difficult to assess the value of the routine use of antibiotics. Oral penicillin has been used in the present series ever since it became available, reinforced by other antibiotics if an intercurrent infection occurred. This has been quite successful, and it has not been necessary to reduce steroid dosage because of infection. Prophylactic antibiotics or sulphonamides have been used to try to prevent intercurrent infections, but they have not been successful.

\section{Note on Congenital Nephrosis}

Three of the children in the 1945-57 series manifested the nephrotic syndrome at or within a few weeks of birth and all died. Two of these were siblings (boy and girl) whose parents were first cousins and they have been reported elsewhere together with a third case (not in the Great Ormond Street series) whose parents were also cousins (Giles, 1957). Briefly, the post-mortem changes were mainly in the proximal tubules, and doubly refractile crystals were present. It is likely that the whole condition was related to cystinosis.

The third child in the present series was the first child of unrelated parents who have since had a normal child. Her eyes were reported as swollen at birth and there was a sudden weight gain about the tenth day. Generalized oedema appeared at about the fourth month. She was given mersalyl at another hospital and later referred here because of a persistent urinary tract infection. Her condition satisfied the four criteria for nephrosis and no improvement was achieved by the use of thyroid extract, blood transfusion, urea or decapsulation of the kidneys. The kidneys at operation were pale and soft with no scarring. No biopsy was done. A year later on re-admission she had no oedema but the blood pressure was raised to $140 \mathrm{~mm}$. $\mathrm{Hg}$, the blood urea was $340 \mathrm{mg} . \%$ and there was an albumin- uria of $650 \mathrm{mg} . \%$ She died at home at the age of $2 \frac{1}{2}$ years. No autopsy was performed.

Another infant admitted to The Hospital for Sick Children in February, 1958, born after a normal pregnancy and delivery and weighing $5 \frac{1}{2} \mathrm{lb}$., developed generalized oedema on the third day of life. (He was the first child of the present marriage of unrelated parents; the mother had had two normal children by a former marriage.) The oedema subsided after two days and recurred at the age of four weeks, leading to admission under the care of a colleague (Dr. A. P. Norman). The infant satisfied the four criteria of nephrosis and electrophoresis showed a typical nephrotic pattern. Urinary amino-acid excretion was within normal range. He was treated with steroids and antibiotics. Very troublesome diarrhoea caused great difficulties in oral feeding and he died after a sudden collapse at the age of $3 \frac{1}{2}$ months. Autopsy (Dr. M. Bodian) showed bilateral renal vein thrombosis of long standing with some extension into the inferior vena cava. The changes in the kidneys were those associated with nephrosis.

These five cases illustrate various ways in which nephrosis may be caused very early in life. Poisoning by mercury is another possible factor. The position briefly is that congenital nephrosis or neonatal nephrosis is likely to be due to mechanisms other than those causing the more usual type of nephrosis such as is dealt with in the present report.

\section{Summary and Conclusions}

A study of nephrosis as seen at The Hospital for Sick Children during the last 40 years has been made. The cases have been divided into three groups: (1) pre-antibiotic 1917-38; (2) antibiotic, and (3) steroid. The recovery rate in the first group was approximately $50 \%$ and much of the mortality was due to infection. In those survivors followed-up in this group there was no instance of relapse after the final hospitalization period. The recovery rate in the second group was $53 \%$ and in the third $40 \%$, and in these last two groups the mortality from uraemia was very much higher.

While the control of infection and of water balance has clearly improved the short-term prognosis, none of the other methods of treatment, including shortterm steroid therapy, appears to have had any very striking effect on the mortality.

Before there was any method of treatment which strikingly affected the basic sign of proteinuria and its associated biochemical disturbances, attention was focused on the control of infection and on the treatment of oedema. Experience has shown that the treatment of oedema per se is not particularly 
important except when the oedema is so severe as to be disabling in itself.

The observation that steroids could bring about a complete biochemical remission in the large proportion of cases has switched attention from protective and palliative treatment to the idea of curative treatment. With the advent of steroid therapy therefore the aim has become the complete reversal of all the pathological changes.

The results of various types of therapy have been compared. Until the technique of prolonged (six-12 months) steroid therapy was introduced, no specific therapy appears to have shown any advantage over simple basic dietary therapy and the control of infection with antibiotics.

Results in a small number of cases in whom long continued cortisone therapy has been given suggest, however, that permanent remissions may be obtained by this means, and raise the hope that the suppression of the biochemical disease in this way may reduce the incidence of that secondary nitrogen retention and hypertension which have become the major cause of mortality in recent years.

There is a high natural tendency to recovery. If all avoidable intercurrent incidents are excluded the natural remission rate is between 60 and $70 \%$. In a reasonable proportion of cases of nephrosis spontaneous remission occurs within the first few months of the disease. As there is no evidence in this series that early treatment gives a better prognosis than that obtained when steroid treatment is delayed for some months from the onset of the disease, and since there are undoubted hazards from the use of steroids, it is suggested that steroid treatment of a new case should be delayed for a month or so to exclude the possibility of an early natural remission.

In our view the present aims of treatment should be as follows:

(1) The control of infection with antibiotics
(2) The maintenance of nutrition as far as possible with a moderately high protein intake

(3) The partial control of oedema with a lowsodium (but not a sodium-free) diet

(4) Long-term treatment with steroids in variable dosage sufficient to maintain urinary protein excretion at the lowest possible level.

By these methods it should be possible to maintain affected children in as good health as possible during the active phase of the disease, and to keep them out of hospital for most of the time, thus interfering with their lives as little as possible.

The success of long-term steroid therapy must be judged by the extent to which it reduces the incidence of renal failure, which has become the major cause of mortality.

Five fatal cases of congenital nephrosis are reported, with varying underlying pathologies.

Thanks are cordially expressed to colleagues on the staff of The Hospital for Sick Children, Great Ormond Street, for permission to include the records of their patients and in some instances to follow up the course of the disease; also to the Department of Medical Illustration for the histograms, and to secretarial staff for much patient typing and re-typing of drafts. The investigations recorded were undertaken under the auspices of the Research Committee of The Hospital for Sick Children.

\section{REFERENCES}

Giles, H. Mc., Pugh, R. C. B., Darmady, E. M., Stranack, F. and Woolf, L. I. (1957). The nephrotic syndrome in early infancya report of three cases. Arch. Dis. Childh., 32, 167.

Mann, W. N. (1958). Bright's disease: the changing concept of a century. Guy's Hosp. Rep., 107, 323.

McCrory, W. W. and Fleisher, D. S. (1958). The nephrotic syndrome. In Recent Advances in Pediatrics, ed. Gairdner, D. 2nd ed. p. 227, Churchill, London.

Metcoff, J. (1958), Editor. Proceedings of the Ninth Annual Conference on the Nephrotic Syndrome. New York.

Payne, W. W. and Wilkinson, R. H. (1951). Nephrotic oedema treated with an ion-exchange resin. Lancet, $2,101$.

Riley, C. M. and Scaglione, P. R. (1959). Current management of nephrosis. Pediatrics, 23, 561 .

Vernier, R. L., Farquhar, M. G., Brunson, J. G. and Good, R. A. (1958). Chronic renal disease in children-correlation of clinical findings with morphological characteristics seen by light and electron microscopy. A.M.A.J. Dis. Child., 96, 306. 